\title{
The Structure of Witnessed Community Violence amongst Urban African American Mothers: Latent Class Analysis of a Community Sample
}

\author{
Cynthia R. Ronzio, ${ }^{1}$ Stephanie J. Mitchell, ${ }^{2}$ and Jichuan Wang ${ }^{3}$ \\ ${ }^{1}$ Sheikh Zayed Institute for Pediatric Surgical Innovation, Children's National Medical Center, Room 655, 111 Michigan Ave NW, \\ Washington DC 20010, USA \\ ${ }^{2}$ Center for Community and Clinical Research, Children's National Medical Center, 6th Floor Research, 111 Michigan Ave NW, \\ Washington DC 20010, USA \\ ${ }^{3}$ Center for Community and Clinical Research, Children's National Medical Center, Room 652, 111 Michigan Ave NW, \\ Washington DC 20010, USA
}

Correspondence should be addressed to Cynthia R. Ronzio, cronzio@cnmc.org

Received 1 July 2010; Revised 23 December 2010; Accepted 17 January 2011

Academic Editor: David Wong

Copyright (c) 2011 Cynthia R. Ronzio et al. This is an open access article distributed under the Creative Commons Attribution License, which permits unrestricted use, distribution, and reproduction in any medium, provided the original work is properly cited.

\begin{abstract}
The prevalence of witnessed community violence (WCV) amongst urban populations in the USA is striking. WCV can be harmful to one's psychological health, and for mothers, the consequences may be more far-reaching as their mental health affects parenting and child development. This study used telephone interviews $(n=209)$ to explore the patterns and covariates of WCV amongst a sample of urban, African American mothers of infants. Mothers reported whether they had witnessed 11 different forms of violence in their current neighborhoods. A latent class analysis revealed two distinct groups of mothers, those with higher versus lowerexposure to WCV. Mothers in the higher-exposure group were more likely to be low-income, to have a high school education or less, and to have higher anxiety scores than those in the lower-exposure group. Depression was not associated with higher exposure to WCV. Distinguishing between higher- and lower-exposure samples can inform the development of targeted prevention and intervention strategies for metropolitan areas.
\end{abstract}

\section{Introduction}

Witnessing violence is a form of exposure to community violence [1], defined as those events occurring amongst strangers or known community or family members that take place in one's neighborhood. Witnessed violence is widely experienced by urban, minority youth $[2,3]$ and urban women of low socioeconomic status [4-6]. Witnessing community violence is potentially harmful to a person's quality of life and psychological health [7-10]. For mothers, the effects of witnessing community violence may be more far reaching as their overall mental health and well-being affects their parenting and children's development. While in general, studies show that women of color have a high prevalence of witnessed violence [4-7], it is uncertain who is at most risk and for what kinds of violence. Thus, the present study examines patterns of witnessed community violence (WCV) in a sample of African American mothers drawn from a metropolitan area.

The public health significance of WCV is underscored by its prevalence as well as by its racial/ethnic and socioeconomic disparities. In a study of urban Latina and nonHispanic White (NHW) women of low socioeconomic status [5], $74 \%$ of the Latina participants reported a lifetime prevalence of witnessing any violence, compared to $59 \%$ of their NHW counterparts. Witnessing lethal violence was less prevalent, but still occurred at disconcerting levels; $10 \%$ of the NHWs and $12 \%$ of the Latinas had seen a knife attack at least once in their lives, and $5 \%$ of the NHWs compared to $13 \%$ of Latinas had ever seen someone shot. In a different 
community-based study of 90 low-income African American women, 59\% reported that they had witnessed some form of violence in their neighborhoods [7]. In a small study of Latina mothers recruited from a Head Start program, Aisenberg [4] reported that $83.9 \%$ of the sample had ever heard gunshots. The prevalence of witnessing lethal violence was also high: $45.2 \%$ reported seeing someone get beaten, $32.3 \%$ had seen a dead body, and $19.4 \%$ had seen someone shot. Stueve and O'Donnell [6] also report frequencies of WCV for an urban sample of predominantly African American women (80.4\%) and Latinas (13.8), approximately one third of whom were mothers. These participants were originally recruited for the study as middle school students and were followed longitudinally through young adulthood. They were asked to report their experiences with witnessing violence, as well as other exposures and concerns, for the last 12 -month period. The authors found high levels of exposure: $79.5 \%$ of this sample had heard guns being shot, $26.2 \%$ had seen someone get killed, and $66.2 \%$ had seen someone beaten up.

There are mixed findings in regards to the mental health consequences of community violence exposure. One study of community violence (measured as recent witnessing, knowledge of, or direct experience of violence) and trauma symptoms amongst low-income African American women found that witnessing community violence was associated with increased traumatic stress [7]. Furthermore, in this study, the effects of domestic violence and witnessing community violence appeared to be additive women experiencing more trauma symptoms if they experienced more than one type of violence. On the other hand, in a study of low-income pregnant women, one-third of whom were African American, community violence did not have a statistically significant effect on mental health functioning, whereas domestic violence was consistently associated with poorer mental health functioning [11]. However, community violence in this study was assessed as a contextual factor; police crime statistics were aggregated at local census block levels, and exposure was inferred. In the aforementioned study of NHW and Latina mothers recruited through an ambulatory neighborhood health clinic, WCV was measured along with the location (either in neighborhood or other locations) and the timing of exposure (within the last year or more remotely, see [5]). The odds of experiencing depressive symptoms for those who witnessed violence in their own neighborhoods were 2.6 times that of mothers who had never witnessed violence in their neighborhoods; the odds increased to 3.9 if the violence was recently witnessed. The odds of experiencing anxiety symptoms were 2.4 and 4.4, respectively. These odds ratios were adjusted for possible confounders including intimate partner violence.

Suglia et al. [12] suggest that distinguishing forms of violence can help clarify the exposures that are most closely linked to quality of life and mental health outcomes and can, therefore, aid intervention research and development. In some studies of witnessed violence, the failure to adjust for severity creates difficulty in interpreting the studies' findings and in developing appropriate intervention and prevention strategies [13]. For example, exposures to lethal violence (such as seeing someone attacked) are likely to be more distressing than hearing a gunshot. Similarly, exposures within one's immediate neighborhood may be more traumatic than if the event took place far from home. Similar measurement refinements may help target interventions and clarify why there are inconsistent findings regarding the association between adult psychological well-being and WCV.

Establishing whether classes or profiles of women with diverse violence exposure exist would significantly assist policy efforts to reduce community violence by targeting interventions for the most at-risk individuals. Such a classification of individuals by their experience of WCV can also serve to monitor reduction in risk overtime and, in terms of policy, can help target interventions for those who are at highest risk for WCV overall and the most traumatic forms of lethal violence in particular. CopelandLinder and colleagues [14] conducted a profile analysis of adolescents who witnessed violence. Their profiles included violence exposure (either witnessed or a direct victim) and the presence of resources (i.e., parental involvement) as a way to gauge groups at varying degrees of vulnerability. The authors argue that person-centered analyses, such as those that establish profiles or typologies, serve a different purpose from variable-centered analyses.

Person-centered analyses cluster study participants into classes or profiles by their similar response profiles; they are designed to more accurately represent people's real experiences and phenomenology. For many years the dominant analytic approaches used in both clinical- and communitybased research have been variable-centered approaches, including ANOVA, multiple regression, mixed (i.e., multilevel) models, and structural equation modeling (SEM). Variable-centered approaches focus on relations among variables and assume the sample under study arises from a homogeneous population. In recent years, finite mixture modeling [14-18] has increasingly gained in popularity as a framework for person-centered analytic approaches. In brief, mixture modeling is a general analytic approach to model population heterogeneity that identifies distinct latent classes (i.e., subgroups) that are unknown a priori and include individuals with shared characteristics, such that individuals within a latent class are more similar than those between latent classes. In the case of our study, using a personcentered approach can reveal groups of women with distinct risks for WCV, or for witnessing a certain type of violence, and whether one group is more at risk for depression or anxiety symptoms.

In the current study, we apply one of the well-known mixture models-latent class analysis (LCA; [16, 19]) — to examine the possible heterogeneity among African American women in the DC metropolitan area regarding their exposure to community violence. Therefore, the aims of the study were twofold. First, we examined WCV items using latent class analysis to establish patterns of violence exposure in this population. Second, we examined whether violence exposure profiles found in the latent class analysis were associated with depression and anxiety symptoms. As there is limited research on WCV in adults, we had no a priori hypotheses. 
However, we did expect those with higher levels of exposure to have worse mental health outcomes.

It is significant that the great majority of studies of community violence focus on economically vulnerable populations [20]. We build on the literature by studying a socioeconomically diverse sample of urban African American mothers in order to provide granularity in the assessment of who is most at risk for witnessed community violence in this potentially vulnerable population.

\section{Methods}

Data for these analyses came from one study within the WIMMN project (Working to Improve Maternal Mental wellNess), a series of investigations on maternal depression in African American mothers. This was a communitybased, cross-sectional study of mothers of 2-18-month-old infants living in the Washington, DC Metropolitan Area. The study was approved by a hospital institutional review board (approval no. 3846).

2.1. Participants and Procedures. Two hundred and nine African American women completed a ninety-minute phone interview about their experiences as mothers of infants and young children. Mothers were recruited between January 2007 and September 2008 from community-based pediatric clinics, and via flyers at daycares, libraries, and community centers. An advertisement of the study was also recorded on a pediatric hospital hold line. Eligibility criteria included: selfidentifying as Black or African American, being a US native and native English speaker, and being a mother of healthy, full-term infant aging 2-18 months who was born in the US. We also limited maternal age to $21-45$ years. Full details of recruitment are reported elsewhere [21].

The interview included depression and anxiety screens, social support and ethnic identity measures, and assessments of three types of violence exposure. Trained interviewers with demonstrated cultural sensitivity conducted the interviews. Participants were paid $\$ 30$.

2.2. Measures. Witnessed community violence (WCV) was measured using a version of the Richters and Martinez Survey of Exposure to Community Violence [22] revised for use with adults. Participants reported how frequently (on a 4-point Likert scale, from never to many times) they had witnessed 11 different types of violence. Examples of items include, "How often have you heard guns being shot?" and "How many times have you seen someone in your home getting shot or stabbed?". They were asked to respond to these questions based on where they lived at the time of the interview in order to establish effects of their current residence and neighborhood. Some respondents may change residences frequently; therefore, questions that seek to place an event in time, for example in the past year, may not address the individual's current risk of witnessing community violence. Further, respondents can both forget serious events that occurred in the past and "telescope" events by placing past events in the current time frame (see [23]). Respondents were asked about events in their current homes and neighborhoods in order to create a natural memory link between events and a specific place in addition to helping assess risk in the respondent's immediate context. The Cronbach's alpha was 0.73 .

Depression was assessed with the Center for Epidemiologic Studies-Depression (CESD) scale [24]. It has been widely used in research with postpartum women and women of color $[25,26]$. It is a 20-point scale that assesses mood, somatic symptoms, interactions with others, and motor functioning. The Cronbach's alpha for this population was 0.91 .

Anxiety was measured with the State-Trait Anxiety Inventory (STAI; [27]), which is a self-report assessment instrument used for separate measures of state and trait anxiety and in distinguishing anxiety symptoms from depressive symptoms. We assessed state anxiety, which reflects a current emotional state in which the respondent tends to respond with anxiety to perceived threats in the environment.

We collected demographic information on maternal age, number and ages of biological children, employment status (full- or part-time), educational attainment (highest level completed, current enrollment), and household members. Income was measured by a single question of family take-home income. Respondents gave weekly, biweekly, or monthly amounts and these were recalculated into yearly income. Educational attainment was recoded into a categorical variable with scores ranging from 0 (less than high school), 1 (completed high school), and 2 (some college attendance, including those with degrees).

2.3. Statistical Analysis. Latent Class Analysis (LCA) was used to analyze patterns of witnessed community violence among the participants. LCA is a type of person-centered analytical approach that helps determine whether there are heterogeneous subpopulations (latent classes) in the target population under study [28-30]. LCA is similar to cluster analysis, but latent class memberships in LCA are based on response probabilities rather than an ad-hoc measurement of distance from group mean. This probability model accommodates unequal degrees of variance for each cluster and can be tested using formal statistical approaches.

Responses to the 11 items drawn from the Survey of Exposure to Community Violence were recoded after examination of their frequency distributions. Two of the items (i.e., exposure to gun shot and arrest) were recoded as three categories: 0-"never exposed," 1-"sometimes exposed," and 2-"often exposed". The rest of the exposure items were recoded as dichotomous: 0- "never," 1-"ever" exposed to the violence (see Table 1).

The LCA modeling process involved several steps. First, various LCA models were explored and compared, and the LCA model with the optimal number of latent classes was identified. Since LCA models with a different number of classes are not nested, it is not appropriate to use the likelihood ratio test for model comparisons, therefore, the Bayesian Information Criterion (BIC) $[32,33]$ and the LoMendel-Rubin likelihood ratio (LMR LR) test [34] were used 
TABLE 1: Frequency of witnessed community violence among african american mothers.

\begin{tabular}{|c|c|c|}
\hline Type of exposure & $N$ & $\%$ \\
\hline \multicolumn{3}{|l|}{ Heard a gunshot } \\
\hline Never & 66 & 31.6 \\
\hline Sometimes & 110 & 52.6 \\
\hline Often & 33 & 15.8 \\
\hline \multicolumn{3}{|l|}{ Saw an arrest } \\
\hline Never & 91 & 43.5 \\
\hline Sometimes & 91 & 43.5 \\
\hline Often & 27 & 12.9 \\
\hline \multicolumn{3}{|l|}{ Saw a drug deal } \\
\hline Never & 132 & 63.2 \\
\hline Ever & 77 & 36.8 \\
\hline \multicolumn{3}{|c|}{ Saw someone beaten up } \\
\hline Never & 148 & 70.8 \\
\hline Ever & 61 & 29.2 \\
\hline \multicolumn{3}{|c|}{ Own home was broken into } \\
\hline Never & 196 & 93.8 \\
\hline Ever & 13 & 6.2 \\
\hline \multicolumn{3}{|c|}{ Saw someone get stabbed* } \\
\hline Never & 199 & 95.2 \\
\hline Ever & 10 & 4.8 \\
\hline \multicolumn{3}{|c|}{ Saw someone get shot* } \\
\hline Never & 190 & 90.9 \\
\hline Ever & 19 & 9.1 \\
\hline \multicolumn{3}{|c|}{ Saw a gun in own home } \\
\hline Never & 193 & 92.3 \\
\hline Ever & 16 & 7.7 \\
\hline \multicolumn{3}{|l|}{ Saw gangs } \\
\hline Never & 146 & 69.9 \\
\hline Ever & 63 & 30.1 \\
\hline \multicolumn{3}{|c|}{ Saw a gun pulled on someone* } \\
\hline Never & 178 & 85.2 \\
\hline Ever & 31 & 14.8 \\
\hline \multicolumn{3}{|c|}{ Saw someone stabbed or shot in own home* } \\
\hline Never & 204 & 97.6 \\
\hline Ever & 5 & 2.4 \\
\hline
\end{tabular}

${ }^{*}$ Exposures to lethal violence.

for selecting the number of latent classes. Lower values of BIC indicate better model fit. A low $P$-value for a LMR LR test indicates that the $(K-1)$-class model has to be rejected in favor of a model with at least $K$-classes. Once the number of classes was identified, observations were classified into their most likely latent classes on the basis of the estimated posterior probabilities for the observations, and the quality of membership classification was assessed via average posterior probabilities and the entropy statistic [31]. Next, the prevalence (i.e., unconditional probability) of participants in each of the latent classes and the conditional probability of specific witnessed violence exposures in a given class were assessed. Finally, the relationships of the latent classes with individual characteristics, such as age, education, household income, and history of child and adult abuse as well as depression and anxiety measures, were examined. These individual characteristics were not included as an explicit part of the LCA model; instead, they were treated as auxiliary variables in the LCA modeling implemented using the statistics program Mplus [31].

\section{Results}

The frequency of witnessed community violence in this sample of urban, African American mothers is shown in Table 1. The majority of participants had heard gunshots $(68 \%)$ and seen an arrest (56\%). A substantial portion had seen drug deals $(37 \%)$ and gangs $(30 \%)$ or had witnessed someone being beaten up (29\%). A relatively small portion of the participants reported witnessing lethal violence, which we define as seeing someone stabbed or shot, seeing someone stabbed or shot in the respondent's home, or seeing someone pull a gun on another person (location unspecified). Few mothers had seen someone stabbed (5\%) or shot (9\%); $2 \%$ had seen someone stabbed or shot in their own homes. A significant minority, 15\%, had seen someone pull a gun on another person.

3.1. Model Selection. LCA models with a different number of latent classes were estimated and compared sequentially (see Table 2). Model exploration stopped when model fit did not improve, with an increase in number of latent classes. Model 2 (with 2 classes) had the smaller BIC compared with Model 1 (with single class), indicating that the 2-class model is preferable. In addition, the $P$-value for the LMR LR test for the 2 -class model was 0.0000 , indicating that the single class model should be rejected in favor of the 2-class model. By increasing the number of latent classes from 2 to 3 , the BIC increased from 2049.75 to 2086.01 , indicating that the 3-class LCA model fit the data worse than the 2-class LCA model. In addition, the $P$-value of the LMR LR test for the 3-class model was not statistically significant $(P=.31)$, indicating that the 2-class model should not be rejected. As such, the 2-class LCA model was the preferred model.

3.2. Quality of Classification. According to Nagin [35], the rule of thumb for the acceptable group classification is that the average posterior probability of correct group membership assignment is $\geq 0.70$. The average individual posterior probability for being correctly assigned to Class 1 was .97, while the average probably of Class 1 members being incorrectly assigned to Class 2 was .05 . Similarly, the average individual posterior probability of being correctly assigned to Class 2 was .95 , and the average probability of being incorrectly assigned to Class 1 instead of 2 was .03. In addition, the value of 0.84 for entropy indicates that the 2class model provides clear classifications [31].

3.3. Latent Class Probability and Class Definitions. The estimated latent class probabilities (i.e., unconditional probabilities or the probabilities of being assigned to a specific latent class) for Classes 1 and 2 were 0.49 and 0.51 , respectively. 
TABLE 2: Comparisons of different LCA models.

\begin{tabular}{lccc}
\hline Model & Description & BIC & LMR LRT P-value \\
\hline 1 & One-class & 2321.825 & NA \\
2 & Two-class & 2049.745 & .0000 \\
3 & Three-class & 2086.014 & .3012 \\
\hline BIC: Bayesian Information Criterion. A smaller BIC indicates a better model fit. LMR LRT: Lo-Mendell-Rubin LR test $P$-value for K-1 Classes. A low $P$-value
\end{tabular}
indicates that the $\mathrm{K}$-1-class model has to be rejected in favor of a model with at least $\mathrm{K}$ classes.

TABLE 3: Latent class probability and conditional probability.

\begin{tabular}{|c|c|c|}
\hline \multirow[b]{5}{*}{ Type of exposure } & \multicolumn{2}{|c|}{ Latent class } \\
\hline & Higher WCV exposure $(N=103)$ & Lower WCV exposure $(N=106)$ \\
\hline & \multicolumn{2}{|c|}{ Latent class probability } \\
\hline & 0.49 & 0.51 \\
\hline & \multicolumn{2}{|c|}{ Conditional probability } \\
\hline \multicolumn{3}{|l|}{ Heard a gunshot } \\
\hline Never & 0.12 & 0.51 \\
\hline Sometimes & 0.56 & 0.49 \\
\hline Often & 0.31 & 0.00 \\
\hline \multicolumn{3}{|l|}{ Saw an arrest } \\
\hline Never & 0.16 & 0.72 \\
\hline Sometimes & 0.58 & 0.28 \\
\hline Often & 0.26 & 0.00 \\
\hline \multicolumn{3}{|l|}{ Saw a drug deal } \\
\hline Never & 0.33 & 0.94 \\
\hline Ever & 0.67 & 0.06 \\
\hline \multicolumn{3}{|c|}{ Saw someone beaten up } \\
\hline Never & 0.44 & 0.97 \\
\hline Ever & 0.55 & 0.03 \\
\hline \multicolumn{3}{|c|}{ Own home broken into } \\
\hline Never & 0.91 & 0.96 \\
\hline Ever & 0.09 & 0.04 \\
\hline \multicolumn{3}{|c|}{ Saw someone stabbed* } \\
\hline Never & 0.91 & 1.00 \\
\hline Ever & 0.09 & 0.00 \\
\hline \multicolumn{3}{|l|}{ Saw someone shot* } \\
\hline Never & 0.82 & 1.00 \\
\hline Ever & 0.18 & 0.00 \\
\hline \multicolumn{3}{|c|}{ Saw a gun in own home } \\
\hline Never & 0.85 & 1.00 \\
\hline Ever & 0.15 & 0.00 \\
\hline \multicolumn{3}{|l|}{ Saw gangs } \\
\hline Never & 0.49 & 0.91 \\
\hline Ever & 0.51 & 0.09 \\
\hline \multicolumn{3}{|c|}{ Saw a gun pulled on someone* } \\
\hline Never & 0.71 & 1.00 \\
\hline Ever & 0.29 & 0.00 \\
\hline \multicolumn{3}{|c|}{ Saw someone shot or stabbed in own home* } \\
\hline Never & 0.95 & 1.00 \\
\hline Ever & 0.05 & 0.00 \\
\hline
\end{tabular}

${ }^{*}$ Exposures to lethal violence. 
TABLE 4: Individual characteristics by latent class $(N=209)$.

\begin{tabular}{|c|c|c|c|}
\hline \multirow{2}{*}{ Variables* } & \multicolumn{3}{|c|}{ Class } \\
\hline & (1) "High risk of violence exposure" $(N=10$ & (2) “ $\mathrm{H}$ & iolence exposure" $(N=106)$ \\
\hline \multirow{2}{*}{ Mean age } & 28.4 & & 29.1 \\
\hline & \multicolumn{3}{|c|}{$\chi^{2}=0.742(P=.389)$} \\
\hline \multicolumn{4}{|l|}{ Education } \\
\hline \multirow{2}{*}{$<$ High school } & $8.3 \%$ & & $5.0 \%$ \\
\hline & \multicolumn{3}{|c|}{$\chi^{2}=0.820(P=.365)$} \\
\hline \multirow{2}{*}{ High school } & \multirow[t]{2}{*}{$45.5 \%$} & \multirow{2}{*}{\multicolumn{2}{|c|}{$25.1 \%$}} \\
\hline & & & \\
\hline \multirow{2}{*}{ College } & \multirow[t]{2}{*}{$46.2 \%$} & \multirow{2}{*}{\multicolumn{2}{|c|}{$68.9 \%$}} \\
\hline & & & \\
\hline \multirow{2}{*}{ Mean household income } & $\$ 27,018$ & \multirow{2}{*}{\multicolumn{2}{|c|}{$\$ 52,860$}} \\
\hline & & & \\
\hline \multirow{2}{*}{ Mean depression score } & 14.0 & \multirow{2}{*}{\multicolumn{2}{|c|}{$=.056)$}} \\
\hline & & & \\
\hline \multirow{2}{*}{ Mean anxiety score } & 34.8 & \multirow{2}{*}{\multicolumn{2}{|c|}{$=.034)$}} \\
\hline & & & \\
\hline
\end{tabular}

* The variables were not an explicit part of the LCA model; instead, they were included as auxiliary variables in modeling. Equality tests of means across classes using posterior probability-based multiple imputations with 1 degree of freedom for the overall test [31].

The conditional probabilities of forms of WCV in Class 1 were much higher than those in Class 2 (Table 3). About $87 \%$ of the participants in Class 1 had ever heard gunshots, including $31 \%$ who had often heard gunshots in their communities. The corresponding figures for having seen an arrest were $84 \%$ and $28 \%$, respectively. In comparison, none of the participants in Class 2 had often heard gunshots or often seen arrests in their communities. The majority of participants in Class 1 had ever seen drug deals (67\%), gangs $(51 \%)$, or someone being beaten up (55\%), while only $6 \%$, $9 \%$, and $3 \%$ of the participants in Class 2 witnessed these events.

All the participants who had ever witnessed lethal violence were in Class 1. Surprisingly, almost one third (29\%) of those in Class 1 had "ever seen someone pull a gun on another person" and $18 \%$ of them had "ever seen someone get shot." In addition, about 5-9\% of the participants in Class 1 had "ever seen someone stabbed" or "seen someone shot or stabbed in their homes." Based on the pattern of conditional probabilities of violence exposure, we define Class 1 as "Higher Exposure to WCV" and Class 2 as "Lower Exposure to WCV."

\subsection{Relationships of Latent Classes with Individual Charac-} teristics. Chi-square tests and one-way ANOVAS testing the associations between individual characteristics and latent class membership were simultaneously implemented with latent clustering (see Table 4). There was no significant difference between the two latent classes in terms of mean age and percentage having less than a high school education. The percentage of high school graduates was much higher in the higher exposure class compared with the lower exposure class, while the percentage of mothers with college education was much higher in the lower exposure class than in the higher exposure class. Family income was also substantially different between the two classes. The mean family income in the lower exposure class was almost double that in the higher exposure class. In regard to mental health measures, the difference in mean scores for depression was only marginally significant, whereas the mean scores for anxiety in the higher exposure class was significantly higher compared to the lower exposure class.

\section{Discussion}

We sought to identify groups of African American mothers of young children distinguished by their self-reported community violence exposures. Suglia et al. [12] suggest that distinguishing forms of violence can help clarify the exposures that are most closely linked to quality of life and mental health outcomes and can, therefore, aid intervention research and development. Establishing whether classes or profiles of women with diverse violence exposure exist would significantly assist policy efforts to reduce community violence by targeting interventions for the most at-risk individuals. This study is particularly relevant as the majority of WCV research focuses on child and adolescents [7] and socioeconomically homogenous populations (e.g., [5-7]). This analysis represents one of the first studies of WCV patterns in a socioeconomically diverse group of mothers of young children.

According to our results, the population under study is heterogeneous in terms of their WCV experience, and could be clustered into higher and lower community violence exposure. The majority of the entire sample had seen an arrest or heard gunshots; however, only the higher exposure group had ever witnessed lethal violence. Previous research on mothers' exposure to community violence also report 
$46 \%$ ever witnessing a physical assault and $19.4 \%$ ever witnessing a shooting [4]. In exploring lifetime prevalence to WCV, $46 \%$ of women had ever heard a gunshot, while $8 \%$ had seen someone shot [5].

The groups were also differentiated based on mental health outcomes and socioeconomic characteristics. The higher exposure group had higher mean anxiety scores possibly because anxiety can clinically resemble posttraumatic stress disorder, a mental health outcome associated with exposure to violence [36]. However, the mean difference was only four points, and the cutoff for clinical significance with this scale is 53 ; therefore, this finding may not be clinically relevant. At the trend level for statistical significance, mean depression scores were higher amongst the high exposure group. While both mean scores (14 and 11) were below the cutoff for clinical significance (CESD $\geq 16$, see [24]), the additional symptoms in the high exposure group, taken together with higher mean anxiety scores implies greater psychological vulnerability in this group and corroborates research on witnessed violence and depression among women $[5,37]$.

It was surprising that half of the higher exposure sample had attended some college or earned a college degree as violence exposure has been implicated in low educational attainment. In a study of violence exposure and school performance in adolescent mothers, both recent (last 12 months) and life-time assessment of exposure to community violence was assessed. In hierarchical models using life-time exposure to violence, WCV predicted poor school performance in three of five categories (suspension/expulsion history, attention problems, and behavior problems, see [38]).

A college background in this population did not necessarily translate into higher earnings or safer residential neighborhoods. Exploratory analysis of education data suggest that the income boost associated with higher education only comes with a completed college degree, not just having attended college. Since new mothers may have interrupted their college career to take care of their infants, the benefits of a college degree may accrue later, once they complete their schooling. The findings suggest, however, that mothers who have not completed college remain economically and physically vulnerable. The high-exposure group was also lower income, and this corroborates other research on the disproportionate amount of violence experienced and witnessed among low-income populations [20]. However, the few studies of women and mothers have focused on low-income populations exclusively (e.g., see [5-7]); our results show that among adult African American women, low socioeconomic status confers risk for WCV.

Alegría et al. [39] argue that as "social inputs" (p. 53) underlie many mental health conditions, policies that target social disparities and social vulnerabilities are of fundamental importance. Given the high association between income and belonging to the higher-exposure group, social policy aimed at reducing poverty (e.g., the Earned Income Tax Credit), promoting employment, and improving education quality and attainment for urban African American women of low SES will be effective in reducing their rates of WCV, and witnessing lethal violence in particular. These polices should include local directives aimed at ensuring cultural effectiveness [40]. Further research into how witnessing violence affects the ability to find work and maintain employment is also needed.

While we classified certain types of witnessed violence as lethal or nonlethal, we also discovered differences in types of lethal exposures. Our participants were twice as likely to witness gun violence compared to knife violence. This is important because guns can result in more fatalities or more serious injuries than other weapons [41], especially amongst bystanders. Thus, witnessing lethal violence may be of particular importance to policy makers. Research has suggested that the more severe types of witnessed violence are more likely to result in psychological distress [42]. Witnessed violence is also frequently associated with other types of violence, and future research on violence in mothers should explore all sources of exposure [13, 43], including perpetration. Multiple types of violence victimization, especially moving from distal to proximate exposures, may also distinguish classes or groups of mothers who are at exceptionally high risk for psychological dysfunction and difficulties in fulfilling their life roles. As we focused on a unique group of women, mothers of infants, this research also calls attention to the need to protect this vulnerable group. The noted prevalence of witnessing nonlethal and lethal violence calls for future research on the effects of witnessed community violence in a metropolitan area on parenting behaviors and infant development.

In contemplating policy to reduce overall violence in America, researchers and policymakers state that violence is essentially preventable [44]. Interventions may be most effective when directed at the social and physical environments. Preventing witnessed community violence may not be feasible if the factors that place women at risk for witnessing are outside their immediate control. For example, a woman's residential neighborhood may be the most significant predictor of witnessing community violence and this is often not a matter of choice for poor women. Therefore, policies and programs that promote safe housing and safe streets and that create communities where lowincome residences are integrated into higher income areas are promising. Community-centered initiatives that include safe and affordable childcare within poor neighborhoods can also help address the needs of mothers of infants who are at risk for witnessing community violence.

This study has several limitations. Participants were drawn from too many neighborhoods to measure neighborhood effects. Future studies may adjust for this by pooling neighborhoods by key characteristics. There are also limitations of the measure of witnessed community violence. We did not determine the exact timing of events, nor whether or not the respondent knew either the victim or perpetrator. While violence was measured based on their current residence, we did not have information on how long they have lived in that residence. The questions also might have yielded unreliable results if the participants did not have a permanent residence, but shared time between homes and friends or family members. Finally, lifetime exposure to WCV was not assessed. 


\section{Conclusions}

Our findings suggest a new approach to measuring witnessed community violence that can help distinguish high- and low-exposure groups. By distinguishing between lethal and nonlethal events and by classifying degree of exposure, we find that risk of witnessing violence, in particular, gun violence, is extremely high for this sample of urban African American mothers. This higher-exposure group was more likely to be low income and have a high school education or less. Distinguishing between high- and low-exposure groups by these characteristics can inform the development of targeted prevention and intervention strategies.

\section{Acknowledgments}

The authors thank an anonymous reviewer for comments on an earlier draft. This research was supported by a grant from NIMH (no. K01 MH069593) to Dr. Ronzio.

\section{References}

[1] S. Overstreet, "Exposure to community violence: defining the problem and understanding the consequences," Journal of Child and Family Studies, vol. 9, no. 1, pp. 7-25, 2000.

[2] C. Campbell and D. F. Schwarz, "Prevalence and impact of exposure to interpersonal violence among suburban and urban middle school students," Pediatrics, vol. 98, no. 3, part 1, pp. 396-402, 1996.

[3] J. D. Osofsky, S. Wewers, D. M. Hann, and A. C. Fick, "Chronic community violence: what is happening to our children?" Psychiatry, vol. 56, no. 1, pp. 36-45, 1993.

[4] E. Aisenberg, "The effects of exposure to community violence upon Latina mothers and preschool children," Hispanic Journal of Behavioral Sciences, vol. 23, no. 4, pp. 378-398, 2001.

[5] C. Clark, L. Ryan, I. Kawachi, M. J. Canner, L. Berkman, and R. J. Wright, "Witnessing community violence in residential neighborhoods: a mental health hazard for urban women," Journal of Urban Health, vol. 85, no. 1, pp. 22-38, 2008.

[6] A. Stueve and L. O'Donnell, "Urban young women's experiences of discrimination and community violence and intimate partner violence," Journal of Urban Health, vol. 85, no. 3, pp. 386-401, 2008.

[7] J. R. Brown, H. M. Hill, and S. F. Lambert, "Traumatic stress symptoms in women exposed to community and partner violence," Journal of Interpersonal Violence, vol. 20, no. 11, pp. 1478-1494, 2005.

[8] S. L. Buka, T. L. Stichick, I. Birdthistle, and F. J. Earls, "Youth exposure to violence: prevalence, risks, and consequences," American Journal of Orthopsychiatry, vol. 71, no. 3, pp. 298310, 2001.

[9] M. Cooley-Quille, R. C. Boyd, E. Frantz, and J. Walsh, "Emotional and behavioral impact of exposure to community violence in inner-city adolescents," Journal of Clinical Child and Adolescent Psychology, vol. 30, no. 2, pp. 199-206, 2001.

[10] M. Cooley-Quille and R. Lorion, "Adolescents' exposure to community violence: sleep and psychophysiological functioning," Journal of Community Psychology, vol. 27, no. 4, pp. 367375, 1999.

[11] G. A. Bogat, K. Leahy, A. Von Eye, C. Maxwell, A. A. Levendosky, and W. S. Davidson, "The influence of community violence on the functioning of women experiencing domestic violence," American Journal of Community Psychology, vol. 36, no. 1-2, pp. 123-132, 2005.

[12] S. F. Suglia, L. Ryan, and R. J. Wright, "Creation of a community violence exposure scale: accounting for what, who, where, and how often," Journal of Traumatic Stress, vol. 21, no. 5, pp. 479-486, 2008.

[13] A. C. Kennedy, "Urban adolescent mothers exposed to community, family, and partner violence: prevalence, outcomes, and welfare policy implications," American Journal of Orthopsychiatry, vol. 76, no. 1, pp. 44-54, 2006.

[14] N. Copeland-Linder, S. F. Lambert, and N. S. Ialongo, "Community violence, protective factors, and adolescent mental health: a profile analysis," Journal of Clinical Child and Adolescent Psychology, vol. 39, no. 2, pp. 176-186, 2010.

[15] Bowen, K. Natasha, Lee, J-S Weller, and E. Bridget, "Social environmental risk and protection: A typology with implications for practice in elementary schools," Children and Schools, vol. 29, no. 4, pp. 229-242, 2007.

[16] C. C. Clogg, Latent Class Models. Handbook of Statistical Modeling for the Social and Behavioral Sciences, Plenum Press, New York, NY, USA, 1995.

[17] B. S. Everitt, Cluster Analysis, John Wiley, New York, NY, USA, 1980.

[18] J. Wang, "Methods and applications of mixture models," Advances and Applications in Statistical Sciences, vol. 3, no. 2, 2010.

[19] L. A. Goodman, "Exploratory latent structure analysis using both identifiable and unidentifiable models," Biometrika, vol. 61, no. 2, pp. 215-231, 1974.

[20] R. J. Turner and D. A. Lloyd, "Lifetime traumas and mental health: the significance of cumulative adversity," Journal of Health and Social Behavior, vol. 36, no. 4, pp. 360-376, 1995.

[21] C. R. Ronzio and S. J. Mitchell, "The highs and lows of maternal depression: cluster analysis of depression symptoms in a sample of African American women," Journal of Investigative Medicine, vol. 58, no. 7, pp. 887-892, 2010.

[22] J. E. Richters and P. Martinez, "The NIMH community violence project: I. Children as victims of and witnesses to violence," Psychiatry, vol. 56, no. 1, pp. 7-21, 1993.

[23] T. A. Wolfer, "'It happens all the time": overcoming the limits of memory and method for chronic community violence experience," Journal of Interpersonal Violence, vol. 14, no. 10, pp. 1070-1094, 1999.

[24] L. S. Radloff, "The CES-D scale: a self report depression scale for research in the general population," Applied Psychological Measurement, vol. 1, pp. 385-401, 1977.

[25] E. J. Corwin, J. Brownstead, N. Barton, S. Heckard, and K. Morin, "The impact of fatigue on the development of postpartum depression," Journal of Obstetric, Gynecologic, and Neonatal Nursing, vol. 34, no. 5, pp. 577-586, 2005.

[26] V. Mosack and E. R. Shore, "Screening for depression among pregnant and postpartum women," Journal of Community Health Nursing, vol. 23, no. 1, pp. 37-47, 2006.

[27] C. Spielberger, State-Trait Anxiety Inventory (Form Y), Mind Garden, Red Wood City, Calif, USA, 1983.

[28] L. M. Collins and B. P. Flaherty, "Latent class models for longitudinal data," in Applied Latent Class Analysis, J. Hagenaars and A. McCutcheon, Eds., pp. 287-303, Cambridge Univerity Press, Cambridge, UK, 2002.

[29] T. Heinen, Latent Class and Discrete Latent Trait Models: Similarities and Differences, Sage, Thousand Oaks, Calif, USA, 1996.

[30] B. Muthén, "Latent variable analysis: growth mixture modeling and related techniques for longitudinal data," in The SAGE 
Handbook of Quantitative Methodology for the Social Sciences, Kaplan, Ed., pp. 345-368, Sage, Newbury Park, Calif, USA, 2004.

[31] B. Muthén and L. Muthén, Mplus User's Guide, Muthén \& Muthén, Los Angeles, Calif, USA, 1998-2008.

[32] A. Raftery, "Bayesian model selection in social research (with discussion)," in Sociological Methodology, P. Marsden, Ed., pp. 111-196, Blackwell, Cambridge, Mass, USA, 1995.

[33] R. Schwartz, "Estimating the dimension of a model," Annals of Statistics, vol. 6, pp. 461-464, 1978.

[34] Y. Lo, N. R. Mendell, and D. B. Rubin, "Testing the number of components in a normal mixture," Biometrika, vol. 88 , no. 3 , pp. 767-778, 2001.

[35] D. S. Nagin, "Analyzing developmental trajectories: a semiparametric, group-based approach," Psychological Methods, vol. 4, no. 2, pp. 139-157, 1999.

[36] R. Yehuda, "Post-traumatic stress disorder," New England Journal of Medicine, vol. 346, no. 2, pp. 108-114, 2002.

[37] C. Nicolaidis, M. Curry, B. McFarland, and M. Gerrity, "Violence, mental health, and physical symptoms in an academic internal medicine practice," Journal of General Internal Medicine, vol. 19, no. 8, pp. 819-827, 2004.

[38] A. C. Kennedy and L. Bennett, "Urban adolescent mothers exposed to community, family, and partner violence: is cumulative violence exposure a barrier to school performance and participation?" Journal of Interpersonal Violence, vol. 21, no. 6, pp. 750-773, 2006.

[39] M. Alegría, D. J. Pérez, and S. Williams, "The role of public policies in reducing mental health status disparities for people of color," Health Affairs, vol. 22, no. 5, pp. 51-64, 2003.

[40] T. B. Bent-Goodley, "Eradicating domestic violence in the African American Community," Trauma, Violence, and Abuse, vol. 2, no. 4, pp. 316-330, 2001.

[41] W. Wells and J. Horney, "Weapon effects and individual intent to do harm: influences on the escalation of violence," Criminology, vol. 40, no. 2, pp. 265-296, 2002.

[42] J. McCauley, D. E. Kern, K. Kolodner, L. R. Derogatis, and E. B. Bass, "Relation of low-severity violence to women's health," Journal of General Internal Medicine, vol. 13, no. 10, pp. 687691, 1998.

[43] E. G. Krug, J. A. Mercy, L. L. Dahlberg, and A. B. Zwi, "The world report on violence and health," Lancet, vol. 360, no. 9339, pp. 1083-1088, 2002.

[44] J. A. Mercy, M. L. Rosenberg, K. E. Powell, C. V. Broome, and W. L. Roper, "Public health policy for preventing violence," Health Affairs, vol. 12, no. 4, pp. 7-29, 1993. 


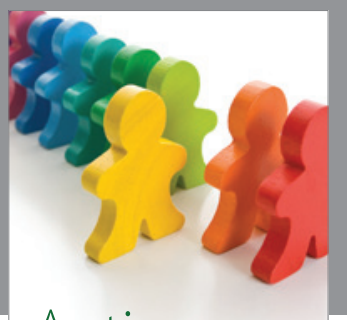

Autism

Research and Treatment
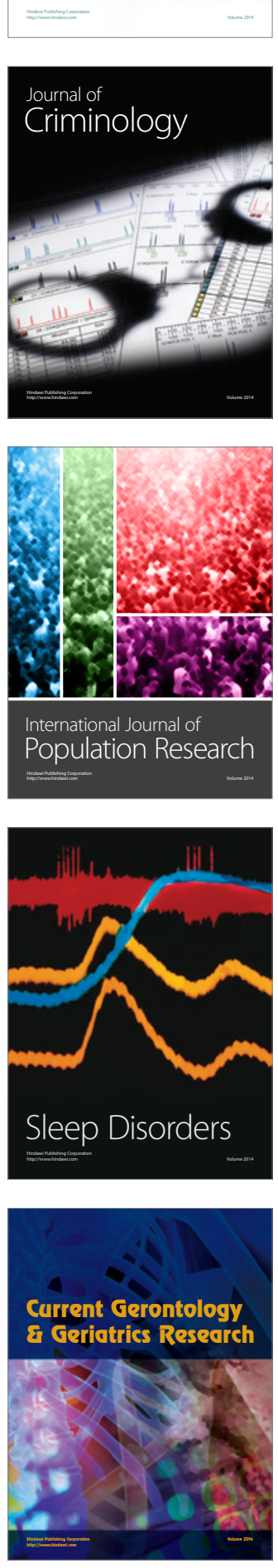
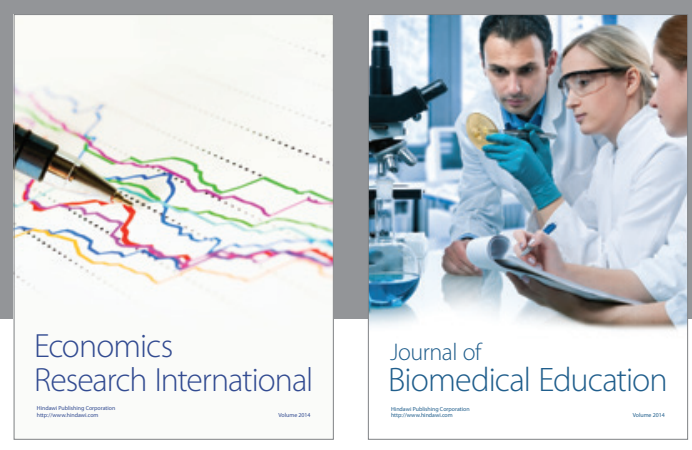

Journal of

Biomedical Education

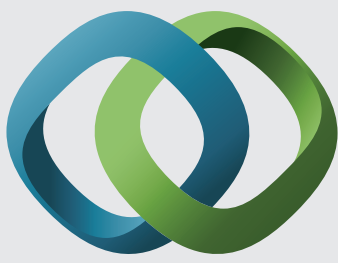

\section{Hindawi}

Submit your manuscripts at

http://www.hindawi.com
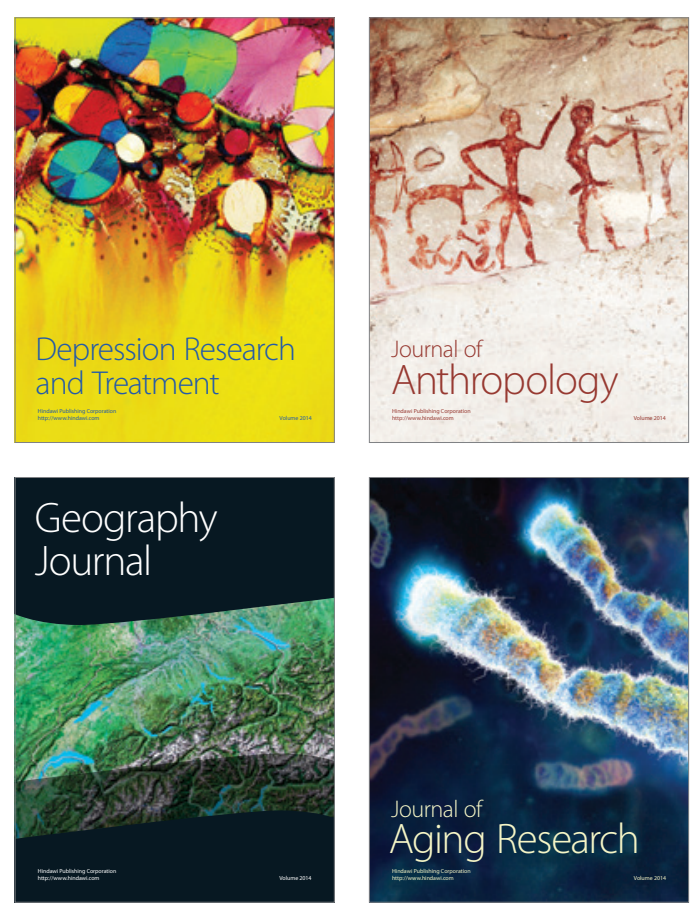

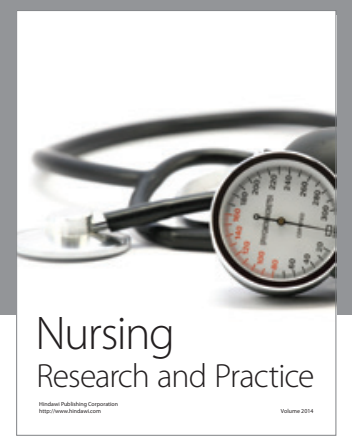

Nursing

Research and Practice

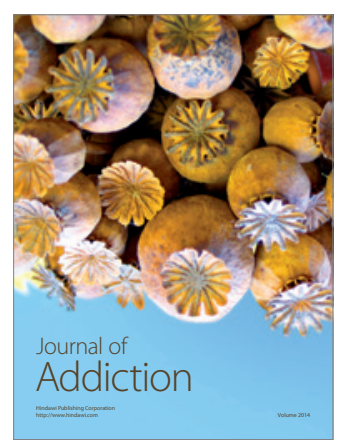

Child Development

Research

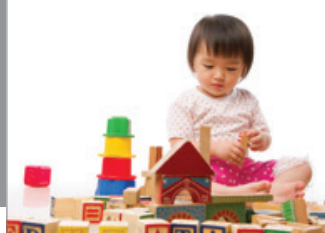

迥
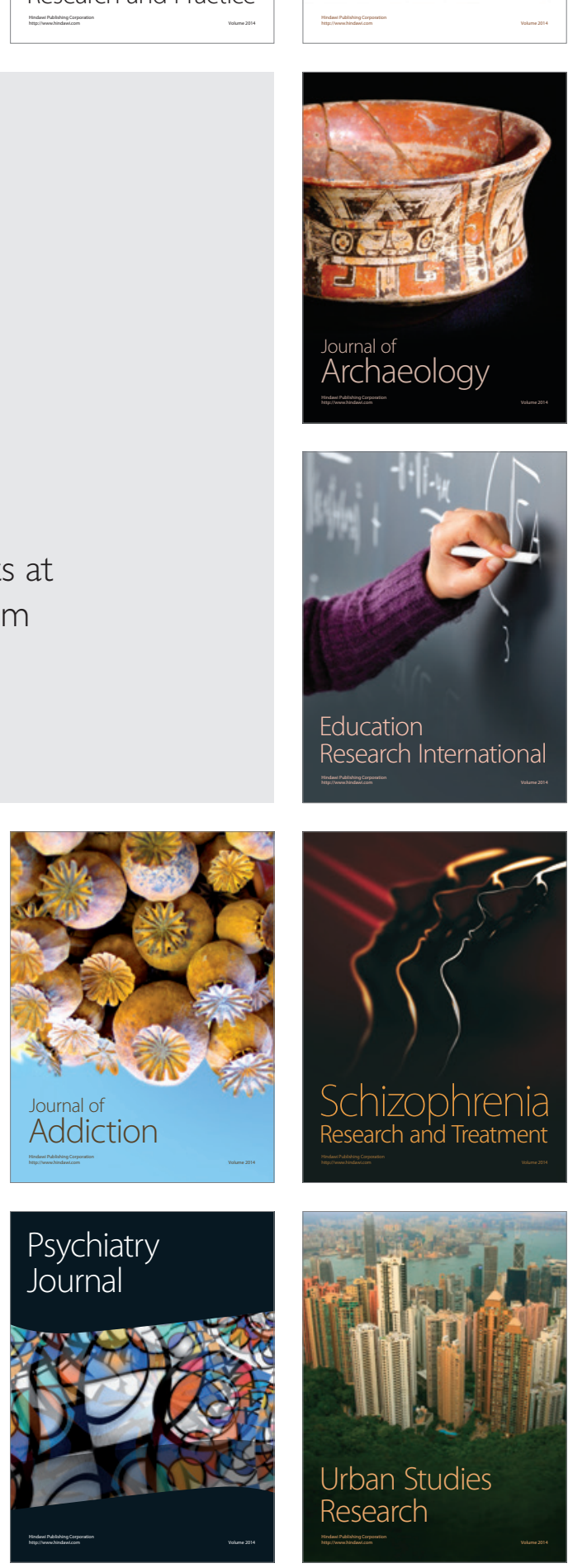